\title{
NEW PERSPECTIVES FOR EDUCATIONAL CARE IN THE HOSPITAL
}

Dott. Ferro Laura, Dott. Marchini Grazia, Dott. Inclimona Cristian, Dott. Doria Serena, Dott. Santoro Caterin

KEYWORDS: Educational care, hospital, skills, professional educator

\section{ABSTRACT}

In places of treatment there are echoes of needs that are unexpressed or that have not been reached, as Lido Valdrè 1 claims, contemporary medicine has reached extraordinary levels of knowledge and operational capacity, yet the relationship between the patient and medicine is yet to be fully comprehended.

In the specific regulations of the medical-health professions, among the most distinctive aspects emerges the relational-educational one: health education, therapeutic and prevention education, development of empowerment in the patient. The hospital, being a complex organization in continuous change towards modernity, hyper-specialization and research, often declines the requests of the staff to be a more mobile and flexible structure, to keep up with the needs of the territory, time and users.

This a frequent request of high demand that does not always correspond to the availability of resources that are at hand. The professional world is considering the possibility of the insertion of a new kind of knowledge, rather of a professional figure of human relationships within the health field. This thought is what has prompted the Research Centre for Pedagogical and Educational Care and the Degree Course in Professional Education of the University of Insubria to take action with the creation of a project of investigation and experimentation in this specific field.

Different hospitals and different departments are required as internship settings for students.

From the many experiments gathered in the projects produced by the students and from the evaluations and references obtained by health care workers, it is possible to hypothesize that the Professional Educator can work with sense and benefit of the subjects involved in the process of care in a hospital environment: a reference figure for the processes of reception, stay and resignation, someone capable of picking up needs and noticing fragility, a proposer of strategies and procedures for intervention and mediation, a curator of the environment and facilitator of relational dynamics.

ido Valdrè, Medicina Muta, p. 20

\section{INTRODUCTION}

A strong and continuous questioning in the new declensions of life that moves from the insidious and innate fear for the condition of illness that brings us back to human fragility, a vulnerability that leads the person to surrender to the cure, as Ivo Lizzola points out. A decision that must be acted upon and not suffered for, an experience that must be accompanied in order to be reignited because it too is a life experience.

What if in this thinking and rethinking, what if in this endless questioning another vision is missing? A profession and a further knowledge that is able to arrive in those dark corners to gather those unborn echoes of need, of support?

These reflections are the origin of the collaborations started with various departments of the hospitals in the province of Varese for an experience of university internship.

Through the surveys carried out in these very places, relevant testimonies of need, research and need for a significant support in the process of care and therefore of re-elaboration of one's own personal experience connected to the breaking of one's own daily life and image both by patients and relatives have been collected and in some occasions even the operators themselves have shown interest and expressed requests for support in carrying out their complex task of care. What has been collected has made it possible to continue the research path of the educational figure in new contexts, continuing from the experimentation started with the master "Educare in Ospedale" (2014/2015) to the insertion of this new area in the internships of the degree course. Precisely because the internship is a powerful training and orientation tool for the student, multiple reworking paths have been offered to better accompany the student in the experience, protecting him/her from possible risks typical of the health care profession, such as Compassion Fatigue and/or Burnout and/or Secondary Traumatic Stress Disorder ${ }^{1}$.

Among the training proposals we offer a group course in the classroom - tutoring (guided by the area tutors) aimed at facilitating and supporting the re-elaboration of the experience and the acquisition and development of critical thinking and socio-relational skills. Moreover, in order to better orient oneself in the field, to acquire awareness of the work environment, of one's own profession, individual meetings with the tutors in the field are available.

\footnotetext{
${ }^{1}$ Article fromJHCEinP (may 2019) UP PADOVA: Compassion Satisfaction e disturbi vicari tra gli studenti di Educazione Professionale durante il tirocinio formativo. Uno studio osservazionale come punto di partenza per l'implementazione di azioni didattiche e di tutoring future (p.47).
} 


\section{METHODOLOGIES}

AND MATERIALS

A fundamental means for the start of the internship is the active agreement between the training institution and the reality that will host the student. To date there are about ten hospital wards of companies in the Varese area with active agreement: hospice, subacute, gynaecology and obstetrics, audiovestibology, pediatrics, geriatrics, neurosurgery, oncology paedriatrics, ats and prevention. New proposals and requests are being considered for coordination, driven by the ward operators themselves or by the interest and contacts of students/tutors.

The training in the field, understood as a process of research-action, provides that the student undertakes a path declined in precise stages of elaboration, of comprihension of the experience and tangible interventions in the operational reality. Each student is called to acquire skills in the analysis of the entry system, in observation, in the identification of the problem/need, in the identification of aims and objectives, in the definition, where possible, of the constitutive project of precise components (methodology, planning, times, places and resources) and, in conclusion, verification and evaluation skills. Such training is possible with the ineluctable support of the operators (therapists or doctors) present in the wards and an attempt to operate as a result of a deontological and experiential practice typical of the educational role. This educational practice is marked by constant supervision by the area tutors, with a view to supervision and training useful for decoding and transforming what has been observed/projected into operations.

The training work in this area can be summarized with the word "silent accompaniment", both for the non-direct cooperativeness of the supervisors and for the slow flow of the interventions that face an already dynamic medical practice made of whirling rhythms. Using the words identified by W. Brandani and P. Zuffinetti in the text "The skills of the professional educator", we could say that even in the hospital context in general the educator feels that "...the journey itself does not protect from possible and sudden changes of direction". As the authors themselves add, the uncertainty of the explorer is at the same time a fundamental part of the entire educational process that refers to the dimension of discovery such as that of the rehabilitative educational practice, to the conquest of a personalized equipment made up of tools of a pedagogical/social/rehabilitative nature, the community dimension that allows one to discover oneself as part of a wide and organic process and the indispensable experience of the unexpected, essential competence in learning to work by supporting oneself.

However, it is fundamental to remember that in order to effectively carry out the mandate of relationship professionals, it is first necessary to get in tune with the environment and with those who occupy it, i.e. the health care workers and technicians present: without their approval and respect at work, intervening would be complex, incomplete and meaningless.
The projects designed and implemented by the students in the wards, in agreement with the staff and their assistants, consist of individual interventions and / or small groups aimed at the overall well-being of the person, the management of free time and waiting for treatment, to improve communication aspects, to facilitate the orientation of patients in the context, to offer opportunities for socializing and entertainment, as well as a good point of comparison on educational, relational and experiential issues with the various professionals and / or relatives.

\section{RESULTS AND DISCUSSION}

The hospital educator is still a figure in the making, although from the experiences already gathered, common functions that are characteristic of the role can be seen.

Here follows the narration of an experience carried out in the gynecology and obstetrics department, reported as an example of a possible educational intervention in the detection of need and the implementation of a specific project.

Role of the professional educator in the design and management of an integrated course of birth accompaniment.

The following work is the result of the internship experience carried out in the Department of Obstetrics and Gynaecology and personal insights with literature research and participation in the 1st Congress of Perinatal Psychology "New perspectives beyond attachment: current cognitive challenges and possible integrations", organized by the Italian Scientific Association of Perinatal Psychology in collaboration with the Sperling Group held in Milan on 25 and 26 May 2019.

Considered for years the exclusive "medical-obstetrical territory", the period of pregnancy and the first days after childbirth remained outside the field of intervention of pedagogy. The traditional view tends to consider the state of pregnancy and the period of puerperium as a sort of parenthesis in a woman's life, during which she would have to deal with a situation of physical limitations to be managed under the direct control of a doctor. This technical vision does not grasp the profound meaning that this experience has in a woman's life and in that of her child and their future relationship.

During pregnancy every couple develops, not without difficulties and problems, a new and fundamental mental structure that will be different from the one they had before: every transition brings with it conflicts, anxieties and fears ${ }^{2}$. All this, already very complex in itself, must also be placed within a society in which "all too often the events of procreation are consumed in the isolation of homes, counseling centers, hospital wards, without the experiences that happen there becoming experience and sediment in a shared culture ${ }^{3}$.

The Lombardy Region, through the establishment of the Birth Path ${ }^{4}$, has recognized that the period before and after childbirth are two special and complex phases in the life of the couple and the child, phases

\footnotetext{
2 D. Stern, N. Bruschweiler, Nascita di una madre, Milano, Mondadori, 1999.

3 S. Vegetti Finzi, Il romanzo della famiglia. Passioni e ragioni del vivere insieme, Milano, Mondadori, 1997, p. 80.

${ }^{4}$ Delibera n. 268 del 28 giugno 2018, "Rete regionale per l'assistenza materno-neonatale: indirizzi per l'appropriatezza e sicurezza del percorso nascita fisiologico a gestione ostetrica"
} 
that involve not only health, but also personal and social aspects, which require a great capacity for adaptation. As it has been set up, the Birth Path requires and relaunches a close collaboration and continuity of care between the territory and the hospital.

In the light of the above considerations, it therefore seems essential:

- To get to know the parents in the period preceding the hospitalization, favoring the continuity of taking charge and creating a truly educational relationship with them that will then facilitate the stay in the Ward;

- to listen and also to try a theoretical categorization of all those experiences that often women and men do not even have the courage to tell;

- $\quad$ orient them towards the territory by illustrating to the couples the various services present and the services provided;

- guiding future parents in the process of empowerment;

- $\quad$ encourage the creation of support networks, especially between couples in the same area who are facing the same path towards parenthood.

All this with the aim of facilitating the early identification of risk factors of a bio-psycho-social nature and improving the well-being of the family that is being formed.

The objective of the project is therefore to assess whether the figure of the professional educator, with his skills, can meet these needs.

Redesigning the pre-birth course from a pedagogical perspective:

- Multidisciplinary management: the interventions are carried out jointly by the midwife and the professional educator, who alternate in the treatment of the topics according to their own competences;

- greater involvement of the fathers, fundamental for the constitution of the new family nucleus;

- rethinking, as far as possible, the spatial setting in order to facilitate communication between the participants and to make the environment personalized and comfortable;

- rethinking of the temporal setting: The course is divided into nine evening meetings lasting two hours each. It is a good idea for the conductor to decide the amount of time to dedicate to each intervention according to the needs expressed by the group and the attention of the participants;

- introduction of new educational contents related to: historical change of the family, what it means to become a father and mother in the hypermodern society, perception and representation of the child, change in the dynamics of the couple after birth, communication modes in difficult moments, difficulties in returning to work, emotions and feelings left unexpressed, etc.

- Implementation of conduction tools, methods and techniques: the material used in the course (posters, blackboard, photocopies, videos, PowerPoint presentations, objects in the delivery room, etc.) can enrich and liven up the conduc- tion, stimulate people and encourage the process of learning and internalisation, increase and maintain attention, increase the creativity of the conductor and encourage group work. It is useful that the conductors alternate theoretical and practical moments, with the aim of welcoming and making people feel at ease, encouraging them to open up to the group and participate in the activities. Leaders can propose drawing or writing autobiographical texts, brainstorming and role-playing activities.

In order to collect the results of the project, I have designed a self-evaluation system. Parents were asked to mark their own position with regard to perceived self-efficacy and their knowledge about the management of the birth path. In addition to the self-assessment, I also provided for interviews that I conducted both in the ward, at the time of actual admission, and in the period after returning home, by telephone.

\section{OBSERVATIONS}

- In the questionnaires, the parents asked to dedicate more time to the study of some topics (e.g. education of the children, motor development of the newborn baby, return to work, etc.);

- The self-evaluation grid showed a homogeneous and constant increase of both theoretical and practical knowledge, learned during the course;

- At the time of the actual admission, the couples were happy to find the educator they met during the Birth Accompanying Course and the interaction in the Ward was facilitated as it had already started before;

- In the questionnaire, the couples state that they have acquired more emotional-relational responses for the self-management of their feelings in moments of difficulty;

- A support network was actually built within the course, between expectant parents, which continued, in some cases, also in the period after the birth;

- Despite the orientation towards the territory and the explanation of the various services offered, couples are still wary of non-hospital services.

From these considerations it can be deduced how much the role and function of the professional educator can be useful, in a perspective of close collaboration with the other professional figures present in the Hospital, in favoring the achievement of the common mission of helping the patient to perceive himself as an active subject in the care of his own state of health. The example reported and the other experiences carried out so far allow us to highlight the versatility of the educational figure, in particular how:

- Professional of observation, reception and reference point for the patient and the family that accompanies him/her throughout the whole process of care.

- Intermediary in relational dynamics and reinforcement for multidisciplinary intervention.

- Supervisor of the environment and builder of a new or transitory daily life; 
- Bringer of quality and new points of view;

- Intermediary between the structure and the territory.

On the whole, the welcoming structures had no difficulty in declaring themselves pleasantly surprised by the educational figure they could hardly frame.
In order to distinguish from the other figures, a new professionalism emerged, without falling into the specter of loss for the figures already present in the staff, of an "other" operator capable of working in a team for the overall well-being of the individual, in a re-compositional perspective with a strong pedagogical-educational value.

\section{REFERENCES}

1. AA.VV. (2014). On the way to the profession - guidelines for the management of traineeships of the CdL in Professional Education, Varese: by the CdL.

2. AA.VV. (2016). In cammino verso la professione - methodological guidelines for the management of traineeships of the BoD in Professional Education, Varese: by the BoD.

3. Bottaro, C. (May 2019). Compassion Satisfaction and vicarious disorders among students of Vocational Education during the training internship. An observational study as a starting point for the implementation of future teaching and tutoring actions. Magazine UP Padova JHCEinP, p. 47.

4. Brandani, W., \& Zuffinetti, P. (2012). The skills of the professional educator. Rome: Carocci.

5. Lizzola, I. (2009). Education in the shadows - educating and caring in fragility. Rome: Carocci.

6. Marchini, G., \& Vender, S. (2017). To educate. The educational care of the sick. Pavia: Medea.

7. Righetti, P.L. (2010). Pregnancy and psychopathological contexts. From theory to intervention tools. Milan: Franco Angeli.

8. Soiffer, R. (1985). Psychodynamics of pregnancy, childbirth and puerperium. Rome: Borla.

9. Stern, D., \& Bruschweiler, N. (1999). Birth of a mother. Milan: Mondadori.

10. Telfener, U. (2010). Learning contexts - Strategies for entering new areas of work. Milan: Ed. Cortina.

11. Valdrè, L. (1995). Muta medicine. The disease between objectivity and feeling. Milan: Rusconi.

12. Vegetti Finzi, S. (1997). The family novel. Passions and reasons for living together. Milan: Mondadori. 